\title{
Effect of microbes on karstification in karst ecosystems
}

\author{
LIAN Bin $^{1 *}$, YUAN DaoXian $^{2} \&$ LIU ZaiHua ${ }^{1}$ \\ ${ }^{1}$ State Key Laboratory of Environmental Geochemistry, Institute of Geochemistry, Chinese Academy of Sciences, Guiyang 550002, China; \\ ${ }^{2}$ Institute of Karst Geology, Chinese Academy of Geological Sciences, Karst Dynamic Laboratory, Ministry of Land and Resources, Guilin \\ 541004, China
}

Received February 28, 2011; accepted June 7, 2011; published online August 30, 2011

\begin{abstract}
The role of microbes in the karstification process was determined based on the karst dynamics, $\mathrm{CO}_{2}$ capture, and carbonate deposition. A close relationship was found among microbial activity, karst dynamics and stability, and the carbon cycle in a karst ecosystem. More in-depth studies were needed to investigate the impact of microbes on karst dynamics within different eco-environments under natural conditions to determine the response of biological organisms to a changing environment, as well as the relationship between microbial organisms and the karstification process.
\end{abstract}

microbes, karst dynamics, carbon-sink stability, carbon cycle, carbonate deposition, carbon capture

Citation: Lian B, Yuan D X, Liu Z H. Effect of microbes on karstification in karst ecosystems. Chinese Sci Bull, 2011, 56: 3743-3747, doi: $10.1007 / \mathrm{s} 11434-011-4648-\mathrm{Z}$

Karstification is a process whereby highly soluble karst stones such as limestone and dolomite are dissolved away or modified via chemical reactions (corrosion and precipitation) in surface and underground water. It is also driven by the mechanical forces from runoff erosion and precipitation, and gravity-collapse erosion. The chemical reactions can be described as

$$
\begin{gathered}
\mathrm{CaCO}_{3}+\mathrm{CO}_{2}+\mathrm{H}_{2} \mathrm{O} \Leftrightarrow \mathrm{Ca}^{2+}+2 \mathrm{HCO}_{3}^{-} \\
\mathrm{CaMg}\left(\mathrm{CO}_{3}\right)_{2}+2 \mathrm{CO}_{2}+2 \mathrm{H}_{2} \mathrm{O} \Leftrightarrow \mathrm{Ca}^{2+}+\mathrm{Mg}^{2+}+4 \mathrm{HCO}_{3}^{-}
\end{gathered}
$$

According to some documented results from laboratory studies, carbonic anhydrase, the enzyme which converts $\mathrm{CO}_{2}$ into $\mathrm{HCO}_{3}^{-}$, participates in the two chemical reactions described above, thus speeding up corrosion of limestone and dolomite [1]. However, $\mathrm{Ca}^{2+}, \mathrm{HCO}_{3}^{-}, \mathrm{CO}_{3}^{2-}, \mathrm{CO}_{2}, \mathrm{H}_{2} \mathrm{O}$, and $\mathrm{CaCO}_{3}$ will rapidly reach a balance under natural conditions. It has therefore been very difficult to define the function of carbonic anhydrase, and even of biological organisms, in the karstification process [2,3].

*Corresponding author (email: bin2368@vip.163.com)
Chemical corrosion of carbonate rocks has been proven in several studies to provide a major carbon sink for atmospheric $\mathrm{CO}_{2}$ (or soil $\mathrm{CO}_{2}$ ) [4,5]. The question is whether soil and petrophilic microbes participate in the karstification process, and, if they do, to what degree they are involved, and which microbial species are present in a karst ecosystem. Answers to these questions could also be helpful in the identification of missing links in the current versions of carbon-cycle models. In addition, studies in this field are very likely to find new functional microbial communities and carbon-capture pathways, thus providing invaluable information to the field of karstification. This research project aimed to identify the karst microbes, to determine the role they play in capturing $\mathrm{CO}_{2}$ and inducing carbonate formation, and to evaluate microbial influences in a karstified ecosystem and the resultant contribution to the carbon cycle.

\section{Varieties and functions of microbes in karst systems}

A microbial population is made up of bacteria, viruses, fungi, 
and some small protozoans. According to an estimate by Whitman et al. [6], there are as many as $4 \times 10^{30}-6 \times 10^{30}$ prokaryotic microbial species on Earth. Because of their rich variety and wide distribution, microbial organisms are found nearly everywhere on Earth, including surface water, underground water, and the surfaces of carbonate rocks. Additionally, these microorganisms are exceptionally recalcitrant. They can rapidly form different types of communities to adapt to various ground environments and to influence the environment in the surrounding area by producing metabolic products from individuals in the population or using the network of interspecies interactions within the communities in which they reside [7]. Microbes are undoubtedly involved in the karstification process.

In recent years, several studies have been reported on microbial diversity in forest soils and peak-cluster depressions in karst regions [8,9], and microbial communities in surface water and underground water environments [10-12]. However, very little is known about the microbes growing on carbonate rock surfaces. Tang et al. [13] used a nonculture method to analyze the microbial diversity on the surfaces of dolostone and limestone rocks. They identified many species of autotrophic bacteria such as the nitrogenfixing and photosynthetic Cyanobacteria, the anaerogenic photosynthetic green non-sulfur bacteria, and heterotrophic bacteria such as Proteobacteria, Actinomycete, and Acidobacteria. A more in-depth analysis determined that there is a rich diversity of karst rock microbes, including fungi and archaeobacteria. In another similar research project by Horath and Bachofen [14], multiple strains of Cyanobacteria were identified on the surface of dolostone in the Alps. The bacterial strains were Leptolyngbya spp., Actinobacteria, Alpha-Proteobacteria, Bacteroidetes, Acidobacteria, Chloroflexaceae; Archaea, amoebas, and eukaryotic microbial green algae were also found. Therefore, it is common for a variety of microbial organisms to reside on the same limestone surface. However, little attention has been given to the role of these microbes during karstification and the impact on the environment resulting from the interaction between these microbes and carbonate rocks.

A few studies have been carried out to identify the determining factors in the karstification process; these studies include laboratory tests on soil-rock-water systems, and field experiments monitoring the karstification rate in soil with different organic matter contents and at various levels of $\mathrm{CO}_{2}$ released by soil respiration [15-17]. However, the microbial role in karst processes and the affecting factors remain unclear. In a case study of the karst system in a peak-cluster depression region in Guilin, China, Pan and Cao [16] attempted to identify the function of karstification in the epikarst zone. The results from this study show that high soil $\mathrm{CO}_{2}$ concentration is a driving force of the karstification process, and the epikarst zone is actually an ecological process occurring in the Earth's surface system. This information is very important for the identification and prediction of microbial functions in the karstification process.

Ding and Lian [18] first isolated microbes from rock surfaces and then used the cultures to study microbial activity during the weathering process of carbonate rocks. The results show that the microbial communities differed significantly in their abilities to dissolve calcium carbonate. The rate of solubilization of calcium carbonate (measured by the released $\mathrm{Ca}^{2+}$ concentration) for the strains FeM002, BYwM020, F8B008, BYB004, and BYB020 were 3.53, 1.90, 1.67, 1.37, and 1.09 times higher, respectively, than that of a pure culture broth control, and 15.29, 8.20, 7.22, 5.93, and 4.73 times higher, respectively, than that of a water control. It is obvious that the microbes were much more efficient at dissolving calcium carbonate than pure physical and chemical weathering processes are. Bacteria with a high acid-producing capacity are not necessarily the most effective in causing weathering of carbonate rocks. Additional factors in this process include the specific proteins and enzymes.

Dou and Lian [19] studied microbial strains of a rockborne fungus (Aschersoni sp.), and they found that fungal mycelia also penetrate and wrap the mineral particles' surface and crack, thus affecting the weathering process. After incubation of the fungus in a calcite-weathering medium, the $\mathrm{Ca}^{2+}$ content in the clear supernatant of the culture was 3.98 and 13.73 times higher than that for a control cultured with dead bacteria and that for pure water, respectively. This result confirmed the strong activity of the fungus in the weathering process of calcite minerals. In contrast to the small single-cell bacteria, fungal mycelia can generate mechanical pressure during penetration of the rocks and by wrapping up particles, thereby expanding the activated surface area of the mineral. This explains why fungi have stronger weathering capacities in general compared with bacteria [20-23].

Therefore, the mechanical pressure from microbes on carbonate rocks is also an important factor affecting their ability to induce weathering of carbonate rocks. In addition, fungi also produce a more complete set of enzymes and a larger variety of metabolic products, and this could be another factor in their more prominent role in mineral weathering compared with that of bacteria.

During weathering of carbonate stones, microbes employ the following three strategies: (1) chemical weathering, in which organic acids and ligands secreted by microbial metabolism control the decay of carbonate rocks; (2) biological physical weathering, where the microbial growth creates physical pressure to break down the mineral particles, for example, fungal mycelial growth penetrating inside mineral rocks, breaking them down to smaller particles, or making the surface of the rocks more accessible to microbial infection and corrosion; and (3) enzymatic weathering, in which enzymes and other active compounds secreted by the bacteria or fungi degrade carbonate rocks.

Growth and metabolism of microbes are affected by environmental factors. Depending on the environmental con- 
ditions, microbial organisms can employ one or combinations of the three strategies described above in weathering minerals at varied rates. Based on whether the microbes have direct contact with carbonate particles, mineral weathering can be divided into two types: direct and indirect weathering. In indirect weathering, there is no direct contact between the microbes and mineral particles. Weathering is achieved mainly by the acidic metabolic products or enzymes produced by the microbes, which would speed up the karstification process.

The acidic metabolic products secreted by microbes include citric acid and acetic acid, and these acids can degrade and dissolve mineral rocks, including limestone. This process has been described as the major mechanism for chemical weathering or biochemical weathering of minerals [22-25].

Enzymes for carbonate rock weathering belong to the carbonic anhydrase family, and these enzymes are produced by almost all organisms, both autotrophic and heterotrophic. Several studies [26-29] have confirmed that carbonic anhydrases can increase the rate of release of $\mathrm{Ca}^{2+}$ and $\mathrm{Mg}^{2+}$ from carbonate rocks, and the degree of solubility of $\mathrm{Ca}^{2+}$ is positively correlated with the activity of carbonic anhydrases. When the enzymes were supplemented into a karst system, carbonic anhydrases catalyzed the conversion of $\mathrm{CO}_{2}$, and increased the corrosion rate of limestone by almost one order of magnitude [1]. In a natural setting like a river basin, the role of carbonic anhydrases produced by biological organisms in the karstification process has not been validated $[2,3]$. Nevertheless, it is true that citric acid, acetic acid, and other acidic metabolic products produced by microbes influence a karst system by indirect weathering.

Direct karstification caused by microbes is much more effective, but is often neglected. Microbes attach to the surface of, or reside in, cracks in limestone. Growth of biomass and extension and twisting of mycelia, as well as penetration, can result in the activation of the rock surface [20-22], thus producing stronger effects by the microbial acidic metabolic products or enzymes, immediately or later, and speeding up rock weathering and the karstification process.

\section{The capture of $\mathrm{CO}_{2}$ by microbes and induction of carbonate formation}

Wright [30] found needle-fiber calcite in Lower Carboniferous limestone in South Wales. It was postulated that these stones were formed by the calcification of fungal mycelia. A study by Masaphy et al. [31] showed that the mycelial growth of mushrooms promoted deposition of calcium carbonate. During the karstification process, oxalic-acid-producing fungi convert limestone $\mathrm{Ca}^{2+}$ ions into calcium oxalate, which is used as an energy source by some bacteria. In the latter reaction, calcium oxalate is converted into calcium carbonate. Results from a study by Lian et al. [32] indicate that bacterial thallus, metabolic products, as well as the nutrient conditions, all significantly affect the appearance of calcite formation.

Bacterial cultures grown in a broth devoid of nitrogen nutrients contain fewer cells but have a higher exopolysaccharide content compared with cultures grown in a nitrogen-sufficient medium that has a higher cell density but lower exopolysaccharide content. When the former culture was added to a calcite crystallization system, the calcite formed had a smoother surface and larger but fewer crystals. However, when the latter culture was added to the system, the calcite crystals had rougher surfaces with a larger number of, but smaller, crystals [33]. This study suggested that mineralizing sites on the bacterial surface and carbonate anhydrases in the bacterial culture may affect formation of carbonates by absorbing $\mathrm{Ca}^{2+}$ and regulating the balance between the $\mathrm{HCO}_{3}^{-}$and $\mathrm{CO}_{2}$ contents.

In a study by Li et al. [34], it was shown that when apatite was used as the sole calcium and phosphate source, $B a$ cillus mucilaginosus degraded the stone and also simultaneously produced calcium carbonate. This was because the bacterium has a high affinity with positively charged ions $[35,36]$, and the carbonic anhydrase derived from the microbe was used to catalyze the hydration of $\mathrm{CO}_{2}$. Under natural conditions, the reaction of calcium carbonate formation induced by microbes is in the opposite direction to that of the karstification process. However, it is still possible to increase the carbon sink, and the carbonate compounds will re-enter the karstification cycle, thus affecting the progress of the original process.

Hou et al. [37] conducted a study on a soil-borne strain, Aletnaria sp., which uses nitrate as a nitrogen source. This fungal strain can actually use $\mathrm{Ca}\left(\mathrm{NO}_{3}\right)_{2}$ as a nitrogen source via the reduction of $\mathrm{NO}_{3}^{-}$to $\mathrm{NH}_{4}^{+}$by nitrate reductase and nitrite reductase; this causes an increase in the $\mathrm{pH}$ value of the medium. The $\mathrm{Ca}^{2+}$ ions in the medium react with the $\mathrm{CO}_{2}$ released by fungal respiration, or with $\mathrm{HCO}_{3}^{-}$, to form calcium carbonate. According to a prediction by Galloway et al. [38], global atmospheric nitrogen deposition will continue to increase in the next decade; atmospheric nitrogen oxides will eventually enter soil and water systems in the form of nitrates. Then the nitrate reduction reaction will increase the soil $\mathrm{pH}$ value. Thus, higher nitrogen deposition will not only enhance $\mathrm{CO}_{2}$ uptake by photosynthesis, but, theoretically, it could also promote the formation of soil carbonates, thus reducing the amount of $\mathrm{CO}_{2}$ released by soil respiration. In the karst region of southwest China, the soil and water systems have high calcium contents, and have high potential for fixing $\mathrm{CO}_{2}$ and forming new carbonates. Soil could act as a sink for atmospheric $\mathrm{CO}_{2}$ by the uptake of $\mathrm{CO}_{2}$ through a geochemical soil system, atmospheric $\mathrm{CO}_{2}$ could be captured and convertd into solid-phase carbon components at high $\mathrm{pH}$ values and under calcium-rich conditions [17]. Identification of the role of microbes in this process should be intensively studied. 
In a field monitoring experiment, Liu et al. [39] found that the global water cycle is likely to produce an important sink for $\mathrm{CO}_{2}$ by dissolution and absorption of $\mathrm{CO}_{2}$ into the water. The rate of this process would increase with increasing carbonate dissolution and increasing $\mathrm{CO}_{2}$ consumption by aquatic plants through photosynthesis.

The uptake of inorganic carbon by microbes, especially the heterotrophic species, is not given sufficient carbon-sink credits in the current generation of carbon-cycle models. A study by Zhang et al. [40] indicates that when B. mucitaginosus was cultured under defined conditions, it was able to use carbonic anhydrase activity to hydrate atmospheric $\mathrm{CO}_{2}$; then the product, $\mathrm{HCO}_{3}^{-}$, entered some of the metabolic pathways of the bacteria. This suggests that $\mathrm{HCO}_{3}^{-}$dissolved in karst underground water, as well as in rivers, streams, and ocean, is not only used by photosynthetic microbes, but a portion of the pool can also enter non-photosynthetic microbes. The presence of two users would significantly enlarge the size of the microbial carbon sink. If it can be validated, this hypothesis will be very useful for explaining the unexplained carbon loss in the carbon cycle and the inputoutput imbalance of global $\mathrm{CO}_{2}$. This will be a good subject for future investigations. The participation of $\mathrm{HCO}_{3}^{-}$in microbial metabolism and its conversion into organic carbon will slow down the process of $\mathrm{CO}_{2}$ release and will certainly affect the rate of karstification.

For microbial carbon fixation, some products will re-enter the atmosphere through respiration, but the major portion will feed into the biological cycle or be deposited on the ground. Therefore, the interactions between carbonate rocks and microbes will not only speed up the weathering process of carbonate rocks, but also help to stabilize the carbon sink by uptake of inorganic carbon during the karstification process.

\section{Conclusion}

Microbial activity is one of the most active geological processes on Earth. It plays an irreplaceable role in the karst dynamics system [25]. The role of microbes during karstification is very complex. Under certain conditions, microbes can speed up the process, promoting deposition of $\mathrm{CO}_{2}$. On other occasions, acids derived from the microbial metabolic products can also enhance the solubility of limestone and the release of $\mathrm{CO}_{2}$. Additionally, microbes can use $\mathrm{CO}_{2}$ released by organisms or stored in the atmosphere to induce the formation of carbonate. All of the above-described events can coexist in a karst region; however, which process plays the leading role depends on the ecological environment. To achieve a quantitative evaluation will need systematic field-site monitoring as well as laboratory experimental data. It is obvious that microbes are part of the karst ecosystem under natural conditions. They affect the stability of carbonate rocks and the rate of the karstification, and eventually the micro and macro appearance of the karst regions.

In summary, the karstification process and the carbon cycle in the karst region are closely related to the microbial population. An integrated study of different types of ecological environments will be needed to define the quantitative impact of different microbial communities and metabolic products on the karst process under natural conditions, to determine the response of biological organisms to environmental variation, and to determine the relationship between microbes and the carbon cycle in a karst ecosystem.

We thank the two anonymous reviewers and English editor for their insightful comments and suggestions. This work was supported by the Ministry of Science and Technology of China (2006CB403200), the National Natural Science Foundation of China (40773069), and the National Science Fund for Creative Research Groups (40721002 and 41021062).

1 Liu Z, Dreybrodt W. Dissolution kinetics of calcium carbonate minerals in $\mathrm{H}_{2} \mathrm{O}-\mathrm{CO}_{2}$ solutions in turbulent flow: The role of the diffusion boundary layer and the slow reaction $\mathrm{H}_{2} \mathrm{O}+\mathrm{CO}_{2} \leftrightarrow \mathrm{H}^{+}+\mathrm{HCO}_{3}^{-}$. Geochim Cosmochim Acta, 1997, 61: 2879-2889

2 Liu Z, Dreybrodt W, Wang H J. A new direction in effective accounting for the atmospheric $\mathrm{CO}_{2}$ budget: Considering the combined action of carbonate dissolution, the global water cycle and photosynthetic uptake of DIC by aquatic organisms. Earth-Sci Rev, 2010, 99: $162-172$

3 Liu Z, Dreybrodt W, Liu H. Atmospheric $\mathrm{CO}_{2}$ sink: Silicate weathering or carbonate weathering? Appl Geochem, 2011, 26: s292-s294

4 Yuan D X. Carbon cycle and global karst. Quat Sci, 1993, 1: 1-6

5 Liu Z. Two important sinks for atmospheric $\mathrm{CO}_{2}$, Chinese Sci Bull, 2000, 45: 2348-2351

6 Whitman W B, Coleman D C, Wiebe W J. Prokaryotes: The unseen majority. Proc Natl Acad Sci USA, 1998, 95: 6578-6583

7 Xu M Y, Sun G P, Guo J. Advances in microbial eco-systems metabolic network study —A review. Acta Microbiol Sin, 2010, 50: 438-443

8 He X Y, Wang K L, Yu Y Z, et al. The responses of soil microbial taxonomic diversity on vegetation communities and seasons in karst area. Acta Ecol Sin, 2009, 29: 1763-1769

9 He X Y, Su Y R, Liang Y M, et al. Soil microbial diversity in typical Karst peak-cluster depression under effects of different defarming patterns. Chin J Appl Ecol, 2010, 21: 317-324

10 He Q F, Yang P H, Yuan W H, et al. Using chemical and microbiological indicators to track the recharge of underground rivers in a karst valley. Hydrogeol Eng Geol, 2009, (3): 33-38

11 Zou S Z, Deng Z P, Liang B, et al. The mechanism of microbe transport in karst aquifer systems. Environ Poll Control, 2010, 32: $1-4$

12 Feng H F, He Q F, Xie S Y, et al. Evaluation and analysis of the rural drinking water quality in Chongqing karst mountainous regions-A case study on Shiqing Village of Nanping Town in Nanchuan district. Earth Environ, 2010, 38: 54-58

13 Tang Y, Lian B, Dong H L, et al. Endolithic bacterial communities in dolomite and limestone rocks from the Nanjiang Canyon in Guizhou karst area (China). Geomicrobiol J, 2011, (in press)

14 Horath T, Bachofen R. Molecular characterization of an endolithic microbial community in dolomite rock in the central Alps (Switzerland). Microb Ecol, 2009, 58: 290-306

15 Yuan D X, Jiang Z C. Research progress of IGCP 379 "Karst Processes and the Carbon Cycle" in China. Hydrogeol Eng Geol, 2000, (1): 49-51

16 Pan G X, Cao J H. Karstification in epikarst zone: The earth surface ecosystem processes taking soil as a medium. Carsol Sin, 1999, 18: 287-296 
17 Pan G X, Cao J H, Zhou Y C. Soil carbon and its significance in carbon cycling of earth surface system. Quat Sci, 2000, (4): 325-334

18 Ding L J, Lian B. Experimentation of microbial weathering to $\mathrm{CaCO}_{3}$. Carsol Sin, 2008, 27: 197-200

19 Dou C W, Lian B. Microbial weathering of calcite by rock-inhabiting fungi. Acta Mineral Sin, 2009, 29: 387-391

20 Jongmans A G, Van Breemen N, Lundstrom U, et al. Rock-eating fungi. Nature, 1997, 389: 682-683

21 Sterflinger K. Fungi as geologic agents. Geomicrobiol J, 2000, 17: 97-124

22 Gorbushina A A. Life on the rocks. Environ Microbiol, 2007, 9: 1613-1631

23 Lian B, Chen Y, Zhu L J, et al. Effect of microbial weathering on carbonate rocks. Earth Sci Front, 2008, 15: 90-99

24 Gadd G M. Geomycology: Biogeochemical transformations of rocks, minerals, metals and radionuclides by fungi, bio-weathering and bioremediation. Mycol Res, 2007, 111: 3-49

25 Cao J H, Yuan D X, Pan G X, et al. Preliminary study on biological action in karst dynamic system. Earth Sci Front, 2001, 8: 203-208

$26 \mathrm{Li} \mathrm{W}, \mathrm{Yu} \mathrm{L} \mathrm{J}, \mathrm{He} \mathrm{Q}$ F, et al. Effects of microbes and their carbonic anhydrase on $\mathrm{Ca}^{2+}$ and $\mathrm{Mg}^{2+}$ migration in column-built leached soillimestone karst systems. Appl Soil Ecol, 2005, 29: 274-281

$27 \mathrm{Li} \mathrm{W}, \mathrm{Yu} \mathrm{L} \mathrm{J}, \mathrm{Wu} \mathrm{Y}$, et al. Enhancement of $\mathrm{Ca}^{2+}$ release from limestone by microbial extracellular carbonic anhydrase. Bioresour Technol, 2007, 98: 950-953

28 Nathalie F M, Lorraine C, Alain C P. Biocatalytic capture of $\mathrm{CO}_{2}$ with carbonic anhydrase and its transformation to solid carbonate. $\mathrm{J}$ Mol Catal B-Enzym, 2009, 60: 163-170

29 Sharma A, Bhattacharya A, Singh S. Purification and characterization of an extracellular carbonic anhydrase from Pseudomonas fragi. Proc
Biochem, 2009, 44: 1293-1297

30 Wright $\mathrm{V}$. The role of fungal biomineralization in the formation of Early Carboniferous soil fabrics. Sedimentology, 1986, 33: 831-838

31 Masaphy S, Zabari L, Pastrana J, et al. Role of fungal mycelium in the formation of carbonate concretions in growing media-An investigation by SEM and synchrotron-based X-ray tomographic microscopy. Geomicrobiol J, 2006, 26: 442-450

32 Lian B, Hu Q N, Ji J F, et al. Carbonate biomineralization induced by soil bacteria Bacillus megaterium. Geochim Cosmochim Acta, 2006, 70: 5522-5535

33 Zhou X Y, Du Y, Lian B. Effect of different culture conditions on carbonic anhydrase from Bacillus mucilaginosus inducing calcium carbonate crystal formation. Acta Microbiol Sin, 2010, 50: 955-961

34 Li H, Lian B, Gong G H, et al. The formation of calcium carbonate particles induced by bacteria. Geol J Chin Univ, 2011, 17: 112-117

35 Chen Y, Lian B. Ability of Bacillus mucilaginosus GY03 strain to adsorb chromium ions. Pedosphere, 2005, 15: 225-231

36 Lian B, Chen Y, Zhao J, et al. Microbial flocculation by silicate bacterium Bacillus mucilaginosus: Applications and mechanisms. Bioresour Technol, 2008, 99: 4825-4831

37 Hou W G, Lian B, Zhang X Q. $\mathrm{CO}_{2}$ mineralization induced by fungal nitrate assimilation. Bioresour Technol, 2011, 102: 1562-1566

38 Galloway J N, Levy H II, Kasibhatla P S. Year 2020: Consequences of population growth and development on deposition of oxidized nitrogen. Ambio, 1994, 23: 120-123

39 Liu Z, Dreybrodt W, Wang H. A possible important $\mathrm{CO}_{2}$ sink by the global water cycle. Chinese Sci Bull, 2008, 53: 402-407

40 Zhang Z C, Lian B, Hou W G, et al. Bacillus mucilaginosus can capture atmospheric $\mathrm{CO}_{2}$ by carbonic anhydrase. Afr J Microbiol Res, 2011, 5: 106-112

Open Access This article is distributed under the terms of the Creative Commons Attribution License which permits any use, distribution, and reproduction in any medium, provided the original author(s) and source are credited. 